\title{
The role of the reference building in the evaluation of energy efficiency measures for large stocks of public buildings
}

\author{
Erika Guolo ${ }^{1}$, Lorenza Pistore ${ }^{1, *}$, and Piercarlo Romagnoni ${ }^{1}$ \\ ${ }^{1}$ Department of Architecture and Arts, University IUAV of Venezia, Dorsoduro 2206, 30123 Venezia, Italy
}

\begin{abstract}
With the last European Directive 2018/844/EU, EU Member States have to outline effective strategies for the energy renovation of existing buildings, so as to achieve the objectives set respectively for 2030, 2040 and 2050, taking advantage of new financing instruments. In this process, public buildings are identified as important drivers for energy-behavioural changes among citizens and, in addition, they can benefit from encouraging mortgages for certified energy efficient renovations. However, the problem of dealing with existing public buildings is their sample size combined with the current necessity of significant renovations. In this scenario, the reference building acquires a key role as the starting model for the evaluation of primary energy needs and of retrofit measures. In this work, a reference building selected by a previous work is further analyzed, testing selected potential retrofit interventions by means of model simulation. The implemented measures are then evaluated using a cost-optimal approach, in order to integrate their priority with respect to cost-effectiveness. The aim of the work is to test on a building centrotype selected retrofit measures, to be then extended to the other buildings similar for their main geometrical and thermophysical features.
\end{abstract}

\section{Introduction}

The last European Directive 2018/844/EU [1] has sanctioned the need for the Member States to outline effective plans for the energy renovation of the existing building share, specifying the expected outputs for longterm renovation strategies and prescribing the monitoring of such developments. According to the impact assessment delivered by the Commission, in order to achieve short, mid and long term objectives set respectively for 2030, 2040 and 2050, renovation should be performed at an average of $3 \%$ each year, in a costeffectiveness perspective. Besides, in the legislation a focus is also put on the involvement of financing instruments and incentives, and on the share of best practices to disseminate successful energy efficiency actions. In this process, the role of public buildings was already indicated as a leading one from the previous Standard 2012/27/EU [2], constituting themselves important drivers to stimulate behavioural changes in energy consumptions by the whole community. Public authorities can benefit from encouraging mortgages for certified energy efficient renovations, e.g. through public-private partnerships or energy performance contracts, in order to reduce the perceived risk of the investments, on condition of transparent and accessible advisories. Among public buildings, educational ones have been lately put under the spotlight, because of their complexity due to (i) their particular Indoor Environmental Quality (IEQ) requirements (ii) their heterogeneity in terms both of geometrical and technological features and (iii) their operational schedules. In fact, despite their similar usage and functions, school buildings embrace different sizes, densities and occupation levels, and all these factors lead to a wide differentiation in the energy needs among the entire stock [3]. In literature, different works have been conducted for the assessment of retrofit interventions and energy savings on public buildings, dealing with a single case study at a time. In [4] and [5] different costefficient retrofit scenarios are discussed for typical educational buildings built around 1960-1970, taking into account occupants' wellbeing. In [6] and [7] two Mediterranean case studies are converted into zero energy buildings while considering $I E Q$ aspects. Ascione et al. [8] implement the refurbishment of an ancient university building in Italy by means of model simulation and with the investigation of potential savings. In [9], an historical university building is analyzed considering low-impact retrofit interventions.

However, when dealing with existing public buildings, the first issue consists in their sample size combined with the still current necessity of great and deep renovations. In this scenario, performing a case-by-

\footnotetext{
* Corresponding author: 1pistore@iuav.it
} 
case energy audit, along with the evaluation and validation of Energy Conservation Measures (ECMs), represent a challenging, time and cost-spending perspective. For this reason, there is the need to develop easy and effective ways to analyze and enhance large stock of buildings. In the Directive 2010/31/UE [10]), the key-role of the reference building was already highlighted as the starting model for the estimation of primary energy needs and for the assessment of retrofit interventions. In Pistore et al. [11], the authors proposed a method for a quick identification of the suitable primary interventions in a large stock of school buildings in the Province of Treviso, clustering buildings according to their constructive and technological features and pointing out a reference building for each group. In this work, one among the so identified reference buildings is further and deeply analyzed, testing the identified potential retrofit interventions by means of model simulation. The implemented measures are evaluated using a cost-optimal approach, so as to weight and evaluate their priority with respect to costeffectiveness. The aim of the work is to test the validity of a building centrotype to implement cost-optimal retrofit measures, to be then extended to the other buildings similar for their main geometrical and thermophysical features. The role of the reference building is pivotal, since it could allow a cost and timesaving improvement of the energy performance of large stocks of buildings, without considering one case at a time.

\section{Method}

Energy simulation has evolved in the recent years as a tool for evaluating and enhancing the energy performance of existent buildings, becoming an important instrument of analysis in operation conditions, from the initial to the construction stage of the building, considering also the interactions building-usersenvironment. In this study, the main goal is to identify the cost optimal and cost-effective renovation measures for a selected existent reference building and to evaluate the renovation package that adds more value also considering the co-benefits.

\subsection{Case study}

The proposed work has been conducted on a high school building in Conegliano (TV) in the north-east of Italy, located in the climatic zone E with 2101-3000 degree days. Built in 1985, it hosts about 1,150 students aged from 13 to 19 years old, and consists of 4 floors over the ground plus a basement, for a total floor area of 12,605 $\mathrm{m}^{2}$, a heated volume of $50,845 \mathrm{~m}^{3}$, a compactness ratio of 0.35 and a transparent envelope area of about 2,074 $\mathrm{m}^{2}$. Offices and administration face north-west, while the classrooms are located all around the building, which is provided with two different conditioning system: an all air system for the most part of the school, and radiators in a small classrooms area (Figure 1).
The school has been selected among 41 educational buildings as a reference centroid of a group of 9 elements, with the approach described in a previous work of Pistore et al. [11].

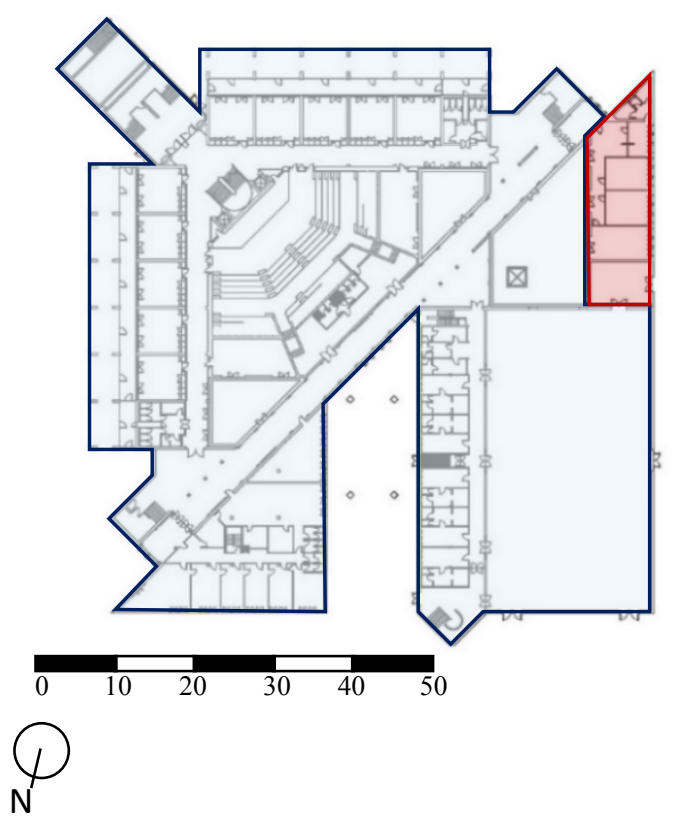

\section{Heating system typology: $\square$ all-air system $\square$ radiators}

Figure 1. School's ground floor map.

In the mentioned approach, buildings are grouped according to their similar geometrical and thermophysical features, by means of clustering techniques. Energy audits are performed by means of the Energy Signatures $(E S)$ method described in the annex B of the superseded standard EN 15603:2008 [12, 13] and the slope of the ES is identified as a synthetic reliable indicator of the energy consumptions. Successively, in a further elaboration of the methodology, the thermophysical features most correlated with the energy consumptions (i.e. the slope of the Energy Signatures) are selected as eligible for interventions, by means of feature selection algorithms, giving a priority of intervention evaluated for each cluster of buildings. In this work, the identified measures are tested on the reference building of one of the clusters, meant to be then extended to the other elements in the same group.

\subsection{The simulation tool}

The thermos-physic model of the school has been realized with OpenStudio [14] (plug-in for SketchUp software) for what concerns the creation of the 3D model and its components, combined with EnergyPlus [15] for the definition of the location, the climate, the internal gains and the system typology for heating and cooling.

\section{Data collection}

In order to obtain the most accurate model, numerous data are needed to be implemented in EnergyPlus: 
- Environmental data: climate data and location (i.e. air temperature, relative humidity, global solar radiation and wind velocity, provided from ARPAV [16] for the 2017-2018 heating season);

- Building data: building geometries, orientation and constructive elements;

- Users data: occupational and illumination profiles (defined according to UNI 10339 [13]) and operational schedules for the system.

\section{Creation of the building's model}

The three-dimensional building model has been created with SketchUp software [17] combined with OpenStudio, implementing the building components (i.e. opaque and transparent envelope) and defining the thermal zones. Successively, the internal gains and the operational schedules for the heating system have been defined in EnergyPlus.

\section{Construction packages}

The construction packages of the building have been implemented considering each material of which they are composed, by means of its main properties: thickness $[\mathrm{m}]$, thermal conductivity $\left[\mathrm{W} \mathrm{m}^{-1} \mathrm{~K}^{-1}\right]$, density $\left[\mathrm{kg} \mathrm{m}^{-3}\right]$, specific heat $\left[\mathrm{J} \mathrm{kg}^{-1} \mathrm{~K}^{-1}\right]$ and other physical properties as emissivity, thermal absorption, and visible absorption.

\section{Thermal zones}

The thermal zones of the selected building have been defined based on the typology and function of the indoor spaces and on their location inside the building. The final model includes 55 thermal zone (Figure 2), belonging to 6 different main types of space (i.e. zones with similar occupational profile: classrooms, offices, bathrooms, corridors, auditorium and gym).

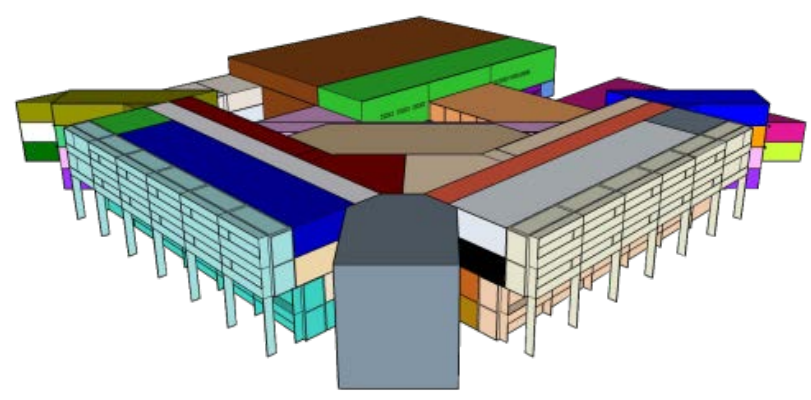

Figure 2. Building model with thermal zones.

\section{Energy retrofit interventions}

\subsection{Intervention features' selection}

The building's features eligible for intervention have been selected by a further development of the work proposed in [11]. The goal was to identify the thermophysical features most correlated to the energy consumptions, namely the slope of the ES. In order to achieve this objective, supervised learning methods were implemented in a stepwise approach: (i) Wrapper Feature Selection to identify the significant features subsets within the initial data set, (ii) Random Forests to give a level of importance of the previously selected features.

According to the results, the following order was observed, from the most important to the least significant measure: thermal transmittance of windows, thermal transmittance of vertical walls to the external environment, thermal transmittance of the roof, thermal capacity of the heating system. This order has been followed in the evaluation of the ECMs proposed hereafter.

For designing the retrofit interventions, the values of transmittance prescribed for 2021 by D.M. 26/06/2015 n. 39 [18] for climatic zone $\mathrm{E}$ have been considered: vertical opaque elements to external or unheated spaces $0.28 \mathrm{~W} \mathrm{~m}^{-2} \mathrm{~K}^{-1}$, roof $0.24 \mathrm{~W} \mathrm{~m}^{-2} \mathrm{~K}^{-1}$, floor $0.29 \mathrm{~W} \mathrm{~m}^{-2} \mathrm{~K}^{-1}$, transparent elements to external or unheated spaces 1.40 $\mathrm{W} \mathrm{m}^{-2} \mathrm{~K}^{-1}$. Besides the enhancement of the thermophysical properties, in order to evaluate the most suitable interventions, a cost-optimal approach has been carried out as prescribed by the European Standards. In this perspective, the global costs for the buildings life cycle have been calculated, following the recommendations of the Commission Delegated Regulation (EU) $\mathrm{N}^{\circ} 244 / 2012$ [19], with a discount rate of $6 \%$ per year [20]. The equation used to estimate the payback time is:

$$
P P=[\text { annual saving }(€) /(1+r)]+\text { investment }(1)
$$

where: $r=6 \%$

\section{Windows renovation}

Regarding the improvement of the window's thermal transmittance, at first windows of classrooms oriented south and east have been considered. The proposed intervention consisted in the substitution with a stratified secure glass, class 2B2 [21] composed by two or more glass layer, assembled with an additional interlayer film (PVB). This type of glass resists to impact from a height up to $4.5 \mathrm{~m}$, holding the glass fragments, limiting the opening dimensions and reduce the risk of wounds or cuts. Furthermore, in order to assure a significant energy saving and good thermal insulation performances, the glass must have a superficial low emissive treatment, so as to limit the transmission of solar radiation while ensuring a high bright permeability. The chosen glass has a thickness of $6.4 \mathrm{~mm}(3 / 0,38 / 3)$ with a total transmittance of $1.0 \mathrm{~W} \mathrm{~m}^{-2} \mathrm{~K}^{-1}$. A PVC material (with inner tube) is suggested for the frame, since it offers a high level insulation without need to maintenance. The frame has a transmittance equal to $1.0 \mathrm{~W} \mathrm{~m}^{-2} \mathrm{~K}^{-1}$. Thus, the total transmittance of the window results $1.15 \mathrm{~W} \mathrm{~m}^{-2}$ $\mathrm{K}^{-1}$.

For what concerns the renovation of windows in the corridors, a glass with thickness $6.8 \mathrm{~mm}(3 / 0,76 / 3)$ and a frame in PVC have been chosen, with a total transmittance of $1.07 \mathrm{~W} \mathrm{~m}^{-2} \mathrm{~K}^{-1}$. Finally, the polycarb skylights at the third floor oriented north and west have been replaced with a polycarb more performing, with a thermal transmittance of $1.1 \mathrm{~W} \mathrm{~m}^{-2} \mathrm{~K}^{-1}$. 
After the replacement of the windows, evaluated by means of the model simulation, the energy usage of the building are reduced of $303 \mathrm{MWh} /$ year, equal to $32.23 \%$ of energy consumptions. As a final step, the proposed intervention has been evaluated by adding to the process the economic variable. An average retail selling price of natural gas equal to $0.39 € / \mathrm{m}^{3}$ for public service activities (source: Italian Regularity Authority for Electricity, Gas and Water - AEEGSI) has been considered. Since the total cost of the intervention, according to the prices defined by the regional prices catalogue of Public Works (Prezziario Regionale Regione Veneto, 2014) [22], is estimated at $€$ $333,041.93$, the economic return is estimated around 30 years. Besides the economic variable, it is important to highlight the potential benefits for occupants in thermal of indoor thermal conditions due to this intervention.

\section{Vertical walls renovation}

For what concerns the vertical walls faced to the external environment, the chosen intervention consists in the insulation with a thermal coat, with the scope of reducing the thermal bridges in the structure and obtain less variations of the internal temperature due to the external climatic conditions (aspect that is of pivotal importance also for occupants' comfort). An EPS panel of $120 \mathrm{~mm}$ thickness and with a thermal conductivity of $0.033 \mathrm{~W} \mathrm{~m}^{-2} \mathrm{~K}^{-1}$ has been chosen. With the application of this panel to the existing wall (next to the more external layer of bricks), the thermal transmittance has improved from $0.7 \mathrm{~W} \mathrm{~m}^{-2} \mathrm{~K}^{-1}$ to $0.227 \mathrm{~W} \mathrm{~m}^{-2} \mathrm{~K}^{-1}$.

With the energy model simulation, the energy demand of the building is reduced of $272 \mathrm{MWh} /$ year, equal to $28.9 \%$ of consumptions. Considering also in this case an average retail selling price of natural gas equal to $0.39 € / \mathrm{m}^{3}$, the total cost of the intervention according to the prices defined by the regional prices catalogue of Public Works [22], is estimated at $€ 209,214.94$. The economic return is estimated around 21 years.

\section{Roof renovation}

Considering the roof of the building, thermal insulation has been added in the existing constructive package, over the concrete screed along with a waterproofing membrane so as to avoid any damage of the insulation material. As previously for the external walls, an EPS panel of $120 \mathrm{~mm}$ thickness and with a thermal conductivity of $0.033 \mathrm{~W} \mathrm{~m}^{-2} \mathrm{~K}^{-1}$ has been selected. With the application of this panel in the roof, and the addition of the floor external layer, the thermal transmittance improves from $0.71 \mathrm{~W} \mathrm{~m}^{-2} \mathrm{~K}^{-1}$ to $0.212 \mathrm{~W} \mathrm{~m}^{-2} \mathrm{~K}^{-1}$. The same constructive package has been used for the gym's roof (previously made of sandwich panels), in order to improve the indoor thermal comfort for the occupants.

Due to the intervention, according to the model simulation, the energy demand of the building is reduced of $109 \mathrm{MWh} /$ year, equal to $11.57 \%$ of consumptions. Considering an average retail selling price of natural gas equal to $0,39 € / \mathrm{m}^{3}$, the total cost of the intervention according to the prices defined by the regional prices catalogue of Public Works [22], is estimated at $€$
$153,403.40$. The economic return is estimated around 38 years.

In Table 1, values for thermal transmittance are specified previous and after renovations, with reference to the requirements set by the standard.

Table 1. U-values of the building's elements before and after renovations.

\begin{tabular}{|c|c|c|c|}
\hline & \multicolumn{3}{|c|}{ U-value $\left[\mathrm{W} \mathbf{m}^{-2} \mathrm{~K}^{-1}\right]$} \\
\hline Element & $\begin{array}{c}\text { before } \\
\text { renovation }\end{array}$ & after renovation & $\begin{array}{l}\text { D.M. } \\
\text { 39/2015 }\end{array}$ \\
\hline Window & $\begin{array}{c}2.17 \text { (classroom) } \\
2.30 \text { (corridor) } \\
5.30 \text { (polycarb) }\end{array}$ & $\begin{array}{c}1.15 \text { (classroom) } \\
1.07 \text { (corridor) } \\
1.10 \text { (polycarb) }\end{array}$ & 1.40 \\
\hline Wall & 0.70 & 0.23 & 0.28 \\
\hline Roof & $\begin{array}{c}0.71 \text { (school) } \\
1.02 \text { (gym) }\end{array}$ & 0.21 & 0.24 \\
\hline
\end{tabular}

\section{Heating system renovation}

Observing the results from the model simulation, it was noticed that the energy consumptions of the building were very high while the plant efficiency was very poor. The causes could be various, from bad maintenance and management of the system, to the typology of the system or the bad distribution design. In order to improve the average seasonal total efficiency (considering the emissions, regulation, distribution and production efficiency) the first step is to operate an ordinary maintenance and cleaning, so as to reduce heat losses, along with improving the distribution system with the application of thermal insulation and by reducing the net dimension of the system. The losses that affect the generator's efficiency can be reduced with a correct design and sizing, avoiding a useless increase of costs and environmental dispersions. An important and crucial measure is to install zone temperature controls or replace the traditional generator with a condensation one.

This latter intervention has been implemented in the simulation model, replacing the obsolete generator with a new condensation one, ensuring an improved efficiency up to $81.7 \%$ (assumes by $80 \%$, with a manual calculate). The efficiencies that determined the seasonal global efficiency are calculated in the following ways: the emission efficiency is determined by standard UNI TS 11300-2 [23], equal to $92 \%$ for vents terminal in the heating air systems; the regulation efficiencies are equal to $96 \%$ [23] for ON/OFF climatic regulation for the system at a lower thermal inertia that manage the temperature in the different zones (classroom, office and gym); the distribution efficiency is considered at $94 \%$, for a centralized system, coats with an accurate thermal and acoustic insulation, applied on the circumference of the conducts.

The renovation of the heating system leads to a decrease in the energy demand of the building up to about $120 \mathrm{MWh} /$ year, equal to a decrease of $12.73 \%$ in the registered consumptions. Considering an average retail selling price of natural gas equal to $0,39 € / \mathrm{m}^{3}$, the total cost of the intervention according to the prices defined by the regional prices catalogue of Public Works [22], is estimated at $€ 7,577.44$. The economic return is estimated around 2 years. 


\subsection{Overall evaluation of retrofit interventions}

In Table 2 an overview of the investment costs for each retrofit intervention is proposed, along with the estimated annual saving and payback time for the investment.

Table 2. Overview of the costs assessment.

\begin{tabular}{|c|c|c|c|}
\hline Element & $\begin{array}{c}\text { Investment } \\
\text { cost } \\
{[\boldsymbol{\epsilon}]}\end{array}$ & $\begin{array}{c}\text { Annual } \\
\text { saving } \\
{[\boldsymbol{\epsilon}]}\end{array}$ & $\begin{array}{c}\text { Payback } \\
\text { time } \\
{[\text { years] }}\end{array}$ \\
\hline Window & $333,41.93$ & $12,440.33$ & 30 \\
\hline Wall & $209,214.94$ & $11,157.09$ & 21 \\
\hline Roof & $153,403.40$ & $4,464.74$ & 38 \\
\hline Heating system & $7,577.44$ & $4,913.64$ & 2 \\
\hline
\end{tabular}

As it can be observed, the investment costs decreases from the highest value for the windows replacement, to the lowest value for the renovation of the heating system. This latter efficiency measure is also the one with the shortest payback time, whereas the roof, wall and windows renovation have a time of return of the investment between 21 and 38 years. On the contrary (Table 2), the windows replacement and the walls improvement would lead to high annual savings with respect to the enhancement of the roof and of the heating system.

At this point, an overall evaluation of the interventions is needed, in order to consider in the decision making process all the assessed aspects. To do this, a weighting methodology has been developed. Each intervention has been evaluated considering three aspects: (i) energy savings, (ii) investment costs, and (iii) payback time. At each aspect a score has been assigned (integer), from 1 (minimum) to 4 (maximum). For instance, a score 1 out of 4 on energy saving means a significant result, on the contrary a score equal to 1 out of 4 on investment cost means a very weak investment. The sum of the given scores is the final value of each intervention: the higher the score the more convenient the measure is.

$\square$ Annual saving $\square$ Investment cost $\square$ Payback period $\square$ Results

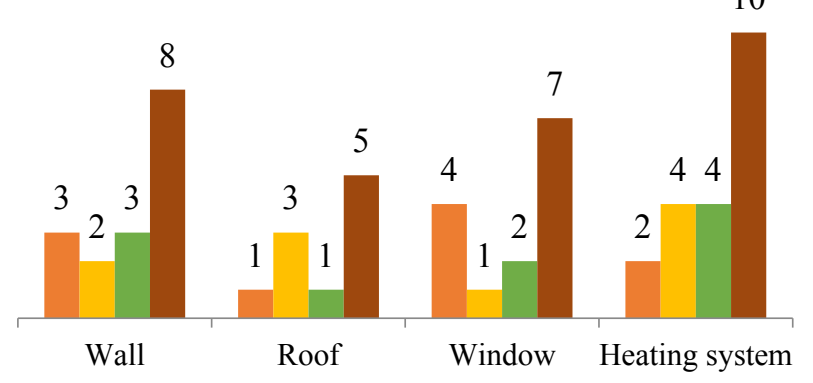

Figure 3. Final evaluation of the interventions
The results are presented in Figure 3. From the plot $t$ is clear that the most efficient and effective measures consist in the renovation of the heating system, the insulation of the vertical walls, the replacement of the windows and finally the application of insulation in the roof.

\section{Conclusions}

In this paper, an educational building is considered to implement and evaluate energy conservation measures by means of dynamic model simulation, using a cost optimal approach. The building was selected as a reference one within a cluster using a previously developed approach. The role of the reference building has gained an increasing importance in the recent years, being identified by the European Directives as the starting model for the estimation of primary energy needs and for testing potential retrofits. In addition to this, public buildings have a central pivotal role, being visible among the community and being drivers for management and behavioural changes. In the proposed work, some selected interventions have been tested on a reference building, in order to estimate the achieved savings both in terms of energy efficiency and life-cycle costs. In this direction, at first the ECMs have been evaluated by means of energy demand reduction, and secondly an economic evaluation has been implemented with a cost-optimal perspective. Finally, an overall assessment has been conducted, assigning a weight of importance. The interventions highlighted as the most convenient are the ones to be implemented, starting from the reference building and then potentially extended to the other buildings in the same cluster.

From this study it is evident how the process of optimizing the renovation of buildings does not account only for energy savings, but also has to consider the lifecycle costs and, nonetheless, the co-benefits and overall added values [20]. Further investigations can be implemented, especially on the side of the impact of such actions on occupants' indoor comfort and wellbeing. Therefore, the choice requires the cooperation of different skills in order to cope with the directives and the legislation of the European Union.

\section{Acknowledgment}

The authors would like to thank the Municipality of Treviso (Provincia di Treviso) for making the data available for this research.

\section{References}

[1] The European Parliament and the Council of the European Union, Directive (EU) 2018/844 of the European Parliament and of the Council of 30 May 2018 amending Directive 2010/31/EU on the energy performance of buildings and Directive 2012/27/EU on energy efficiency, Brussels, Belgium: Official Journal of the European Union L315/1, 2018. 
[2] The European Parliament and the Council of the European Union, Directive 2012/27/EU, on energy efficiency, amending directives2009/125/EC and 2010/30/EU and repealing Directives2004/8/EC and 2006/32/EC,, Brussels, Belgium: Official Journal of the European Union L315/1, 2012.

[3] L. Dias Pereira, D. Raimondo, S. P. Corgnati and M. Gameiro da Silva, "Energy consumption in schools A review paper," Renewable and Sustainable Energy Reviews, vol. 40, pp. 911-922, 2014.

[4] T. Niemelä, R. Kosonen and J. Jokisalo, "Costoptimal energy performance renovation measures of educational buildings in cold climate," Applied Energy, no. 183, pp. 1005-1020, 2016.

[5] X. W. Leong and E. A. Essah, "Bridging the gap between energy consumption and the indoor environmental quality of a 1960s educational building," Energy Procedia, vol. 132, pp. 87-92, 2017.

[6] C. K. Mytafides, A. Dimoudi and S. Zoras, "Transformation of a university building into a zero energy building in Mediterranean climate," Energy and Buildings, vol. 155, pp. 98-114, 2017.

[7] O. Irulegi, A. Ruiz-Pardo, A. Serra, J. M. Salmerón and R. Vega, "Retrofit strategies towards Net Zero Energy Educational Buildings: A case study at the University of the Basque Country," Energy and Buildings, vol. 144, pp. 387-400, 2017.

[8] F. Ascione, N. Bianco, R. F. De Masi, F. de' Rossi and G. P. Vanoli, "Energy retrofit of an educational building in the ancient center of Benevento. Feasibility study of energy savings and respect of the historical value," Energy and Buildings, vol. 95, pp. 172-183, 2015 .

[9] G. Semprini, C. Marinosci, A. Ferrante, G. Predari, G. Mochi, M. Garai and R. Giuli, "Energy management in public institutional and educational buildings: The case of the school of engineering and architecture in Bologna," Energy and Buildings, vol. 126, pp. 365-374, 2016.

[10] The European Parliament and the Council of the European Union, Directive 2010/31/EU of the European Parliament and of the Council of 19 May 2010 on the energy performance of buildings, Brussels, Belgium: Official Journal of the European Union L315/1, 2010, pp. 13-35.

[11] L. Pistore, G. Pernigotto, F. Cappelletti, P. Romagnoni and A. Gasparella, "From energy signature to cluster analysis: an integrated approach," in International High Performance Buildings Conference, West Lafayette, IN, 2016.
[12] CEN - European Committee for Standardization, EN 15603 - Energy performance of buildings. Overall energy use and definition of energy ratings., Brussels: European Committee for Standardization, 2008.

[13] UNI 10339 - Impianti aeraulici al fini di benessere. Generalità, classificazione e requisiti. Regole per la richiesta d'offerta, l'offerta, l'ordine e la fornitura, Brussels: Ente Italiano di Normazione.

[14] “OpenStudio,”[Online].Available: https://www.openstudio.net/.

[15] “EnergyPlus,"[Online].Available: https://energyplus.net/.

[16] Agenzia Regionale per la Prevenzione e Protezione Ambientale del Veneto, "Arpa Veneto," [Online]. Available: http://www.arpa.veneto.it/.

[17] “SketchUp,’[Online].Available: https://www.sketchup.com/it.

[18] Governo Italiano, Decreto Ministeriale 26 giugno 2015 - Applicazione delle metodologie di calcolo delle prestazioni energetiche e definizione delle prescrizioni e dei requisiti minimi degli edifici, Rome, 2015.

[19] European Union Commission, Commission delegated regulation (EU) No 244/2012, 2012.

[20] T. Dalla Mora, F. Peron, T. Romanoni, M. Almeida and M. Ferreira, "Tools and procedures to support decision making for cost-effective energy and carbon emissions optimization in building renovation," Energy \& Buildings, vol. 167, pp. 200-215, 2018.

[21] Ente Italiano di Normazione, UNI 7697 - Criteri di sicurezza nelle applicazioni vetrarie, 2014.

[22] Regione Veneto, "Prezziario Regione Veneto," 2014.[Online].Available:

http://www.regione.veneto.it/prezzario2014/home.aspx.

[23] CEN, UNI TS 11300, part 1 and 2, Brussels: European Committee for Standardization, 2008b.

[24] N. Jurišević, D. Gordić, N. Lukić and M. Josijević, "Benchmarking heat consumption in educational buildings in the city of Kragujevac (Serbia)," Energy Efficiency, vol. 11, no. 4, pp. 1023-1039, 2018.

[25] T. Niemelä, R. Kosonen and J. Jokisalo, "Costoptimal energy performance renovation measures of educational buildings in cold climate," Applied Energy, vol. 183, pp. 1005-1020, 2016. 